\title{
The relationships between plasma cholesteryl polyunsaturated fatty acids, age and atherosclerosis
}

\author{
K. J. KINGSBURY \\ D. M. MORGAN \\ R. STOVOLD \\ C. G. BretT
}

St Mary's Hospital, London, W.2

\begin{abstract}
Summary
The ages, plasma cholesteryl dienoic acid, 2-hr blood sugar and plasma cholesterol concentrations of 146 patients with aorto-iliac and femoro-popliteal atherosclerosis, were compared with their arterial lesions classified into occlusions, irregularities and stenoses by pulses and arteriograms.

The arterial lesions were also compared with the patient's prognosis in terms of the development of angina or myocardial infarction.

The results showed that reduced concentrations of cholesteryl dienoic acids were specifically related to an increase in the number of arterial occlusions, independently of the patients' ages, plasma cholesterol and 2-hr blood sugar levels, arterial irregularities or stenoses.

The arterial occlusions in turn related to the development of myocardial infarction but not angina.

It is concluded that a relationship existed between the reduced concentrations of cholesteryl dienoic acids and the occlusive element of human atherosclerosis which is a major factor in the patient's prognosis.
\end{abstract}

\section{Introduction}

Abnormal concentrations of the plasma cholesteryl ester polyunsaturated fatty acids occur in some atherosclerotic patients (Lewis, 1958; Luddy et al., 1958; Schrade, Boehle \& Biegler, 1960; Bottcher \& Woodford, 1961; Kingsbury et al., 1962b). Recent evidence shows they are related to the development of myocardial infarction (Kingsbury et al., 1969), but like the reduced glucose tolerances (Wahlberg, 1966) which also occur in these patients (Kingsbury, 1968), they seem unpredictable and to be unrelated to the severity of the disease (Schrade et al., 1960). The comparison of the reduced glucose tolerances with the extent and type of the arterial lesions as seen on arteriograms showed, however, that they did not occur haphazardly but were, in fact, related to the atheromatous irregularities of the arterial wall and not to the arterial occlusions (Kingsbury, 1966, 1968). This allowed us to reexamine the relationship between the plasma cholesteryl polyunsaturated fatty acid concentrations and the atherosclerotic arterial disease. Three points were examined: firstly a comparison of the concentrations in normal subjects and patients; secondly a comparison of the concentrations with the arterial lesions; and finally a comparison of the arterial lesions with the development of myocardial infarction.

The results are reported here.

\section{Patients, normal subjects and age groups Patients}

A consecutive series of 146 new male atheromatous patients were admitted to the study following their first visit to the Out-Patient Department (OPD) and who presented with claudication due to aorto-iliac and/or femoro-popliteal atherosclerosis, had arteriograms performed by one radiologist (Dr D. Sutton, Director of the Radiological Department, St Mary's Hospital, London, W.2), were between 35 and 75 years old, and were not on special diets or clofibrate. The studies were restricted to these patients since their arterial disease could be assessed routinely by pulses and arteriograms; this is not possible at present in patients with ischaemic heart disease. Patients with aneurysms were excluded since for clinical reasons not all were able to have arteriograms.

\section{Normal subjects}

Two 'normal' groups were investigated: seventysix male medical students aged 19-23 and thirtynine older normals aged 38-68 consisting of twelve academic staff, fourteen skilled and semi-skilled 
part-manual workers (metal workers, electricians, plumbers, etc.) and thirteen clerical staff.

\section{Age groups}

Three age groups were selected: low (under 55 years), middle (55-64 years) and high (65-75 years) (Kingsbury, 1968).

\section{Methods}

\section{(1) Biochemical}

(a) Concentrations of polyunsaturated fatty acid classes in the plasma cholesteryl esters. The cholesteryl esters were extracted from 5 to $10 \mathrm{ml}$ plasma by shaking with silicic acid (15 g) and methylene dichloride $(100 \mathrm{ml})$.

The extract evaporated at $40^{\circ} \mathrm{C}$ with oxygenfree-nitrogen, was added in hexane on to chromatographic columns of $10 \mathrm{~g}$ silicic acid. The cholesteryl esters were eluted with $250 \mathrm{ml}$ of $2 \%$ diethyl-ether in petrol ether (40-60 b.p.). These were consistently pure as shown by thin-layer chromatography and by negative colorimetric tests for lipid glycerol (modification of Lambert \& Neish, 1950; Kingsbury, 1969, lipid phosphorus (Hawk, Oser \& Summerson, 1947), unesterified cholesterol (MacIntyre \& Ralston, 1954) and unesterified fatty acids (Duncombe, 1963).

The concentrations of the polyunsaturated fatty acids (two to six double bonds termed dienoic, trienoic, tetraenoic, pentaenoic and hexaenoic acids, respectively) in the samples of cholesteryl esters were determined by alkaline isomerization modified from Holman \& Hayes (1958) (Kingsbury, 1969).

Alkaline isomerization appeared the most appropriate analytical method (Herb, Magidan \& Riemenschneider, 1960; Kingsbury et al., 1962a; Kingsbury, Morgan \& Hayes, 1964); it avoided the variable losses in the higher polyunsaturated fatty acids which occur during gas-liquid chromatography (Ackman, Sipos \& Jangaard, 1967), the ultraviolet absorptions provided a constant check on the possibility of oxidation, and it enabled a closer comparison between the test samples than gas-liquid chromatography as many could be analysed in duplicate simultaneously, together with the necessary blanks and standards.

The amount of cholesteryl ester isomerized was determined both from its content of cholesterol (MacIntyre \& Ralston, 1954) and esterified fatty acids (Morgan \& Kingsbury, 1959) using cholesterol oleate as standard.

The absorption values of polyunsaturated fatty acid standards obtained by Holman \& Hayes (1958) were checked against natural dienoic, trienoic, tetraenoic, pentaenoic and hexaenoic fatty acids of over $99 \%$ purity (obtained from The Hormel Institute, Professor E. Klenk, Cologne, and by urea crystallization, chromatography and multistage molecular distillation from cod liver oil with $\mathrm{Dr}$ K. Reed and Dr P. Ridgway Watt) with synthetic cholesteryl arachidonate (Dr Osbonde, Roche Products Ltd), and with pure cholesteryl dienoic, trienoic and tetraenoic esters obtained from human plasma by silver nitrate column chromatography. The isomerization contents of the natural fatty acids, synthetic arachidonate and the corresponding plasma cholesteryl esters were virtually identical (data with K.J.K.).

The samples were run in batches of six plus a control sample of bulked deep-frozen plasma and a 'blank' run with solvents only; and isomerized simultaneously in duplicate together with additional duplicates of bulked deep-frozen cod liver oil to check the isomerization procedure. Plasma samples giving high and low polyunsaturated fatty acid concentrations from the different runs of each month were re-analysed in the same run to check their rankings. The standard deviations of the bulk plasma replicates (run at different times) were: dienoic acids, $1 \cdot 8$; trienoic acids, $0 \cdot 19$; tetraenoic acids, 0.3 ; pentaenoic acids, 0.08 ; and hexaenoic acids, $0 \cdot 27$.

(b) Oral glucose tolerances. The glucose tolerances were estimated using the standard $50 \mathrm{-g}$ oral glucose tolerance test with the blood sugar levels in the fasting, 1- and 2-hr blood samples analysed by hand (Huggett \& Nixon, 1957). Only the 2-hr blood sugar levels are reported here since these were shown to be the most sensitive to changes in the degree of atherosclerosis (Kingsbury, 1966, 1968).

(c) The plasma cholesterol level. The plasma cholesterol levels were estimated by the method of Henly (1957).

The fatty acid and plasma cholesterol concentrations were determined in the fasting samples obtained for the glucose tolerance tests, as soon as possible after the patient's first visit to the OPD and in the same period as their arteriograms were undertaken.

\section{(2) Assessment of the arterial lesions}

(a) By arteriograms. The initial series of lumbar and femoral arteriograms were used to classify the atherosclerotic arterial lesions from the third lumbar vertebra to the main divisions of the popliteal a.teries by their major components-occlusions, stenoses and atheromatous irregularities. The arteriograms were performed by one radiologist $(\mathrm{Dr}$ D. Sutton, Director of the Radiological Department, St Mary's Hospital, London, W.2) according to standard techniques (Sutton, 1962). The occlusions and stenoses were counted separately and graded 
as 0,1 and 2 or more (2+) to correspond with the classification by pulses.

The degree of atheromatous irregularity was grared into three groups as follows:

Slight: arteries which appeared smooth-walled or healthy, or with only an isolated patch of irregularity up to an inch in length.

Extensive : marked irregularities confluent throughout the length of the iliac and/or femoral and/or popliteal arteries

Moderate: irregularities intermediate between 'slight' and 'extensive'.

The patients' irregularities were classified by the most severe grading seen in the iliac, femoral or popliteal arteries.

Plaques were not estimated separately since these were overrun by the more extensive irregularities.

The lesions were classified when the patients were admitted to the study and checked by two further observers unaware of the experimental results. The overall reliability of the arteriographic classification was also checked in over 100 sets of these arteriograms by a second radiologist (Dr H. West. bury, then Senior Registrar, Radiological Department, St Mary's Hospital, London, W.2).

It was found impossible to confuse the arteriographic appearances of slight and extensive irregularities, or patent arteries with those containing multiple occlusions or stenoses. Some doubts were expressed for fifteen of the 146 sets of arteriograms in which the degree of irregularity bordered between either slight and moderate, or moderate and extensive. These patients were given the more severe of the alternative gradings.

(b) By pulses. The patients were classified into three groups, according to whether or not they had absent femoral and/or popliteal pulses, it being accepted that an absent pulse was probably due to a more central occlusion. The absent pulses were recorded by more than one person on at least two occasions. The groups were taken as:

Group 1. Femoral and popliteal pulses present in both legs.

0 occlusion

Group 2. Femoral and/or popliteal pulses absent in one leg.

$1+$ occlusion

Group 3. Femoral and/or popliteal pulses absent in both legs.

$2+$ occlusions

Pilot studies showed these groups to contain adequate numbers for analysis. Analyses within Groups 1 and 2, according to the presence or absence of ankle pulses, revealed no further differences in ages or biochemistry (data available from K.J.K.); hence, only the main groups are presented here.

\section{Results}

Plasma cholesteryl polyunsaturated fatty acid concentrations in normal subjects and patients

The percentage concentrations of the cholesteryl polyunsaturated fatty acid classes, ages, and plasma cholesterol levels of the patients and normal subjects are shown in Table 1. The ' $t$ ' and ' $P$ ' values (Student's ' $t$ '-test) of the differences between them are also shown.

It can be seen that, first, the students and older normals had similar cholesteryl polyunsaturated fatty acid concentrations, even though their ages and plasma cholesterol levels were clearly different. The patients, however, had lower concentrations of dienoic, tetraenoic and hexaenoic, but higher concentrations of trienoic and pentaenoic fatty acids than either normal group. These differences did not result from different plasma cholesterol levelsfor those of the patients and older normals were almost identical; or different ages, for the students had similar fatty acid compositions to the older normals but were clearly much younger. In support of this none of the polyunsaturated fatty acid concentrations were correlated with age in either the older normal or patient groups $(P>0.05) .^{*}$

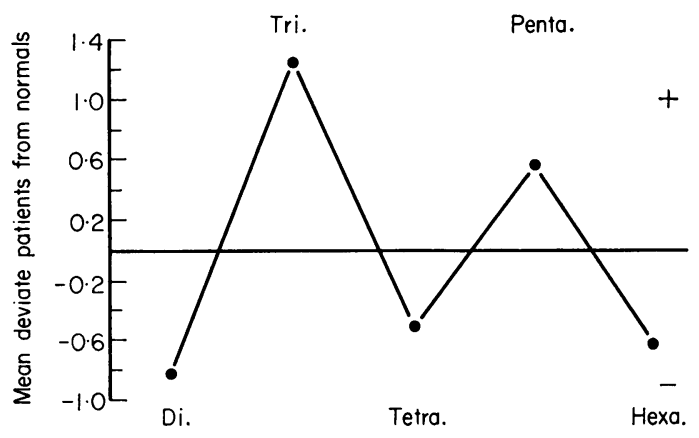

FIG. 1. The inverted ' $w$ ' type of polyunsaturated fatty acid abnormality shown by the mean deviates of the patients' abnormal polyunsaturated fatty acid concentrations from the mean values of the older normals:

$\frac{\text { (Means older normals - Means patients) }}{\text { (Standard deviations of older normals) }}$

The differences in the polyunsaturated fatty acid concentrations between the patients and older normals are shown in Fig. 1.

\footnotetext{
*Correlation coefficients between age and the dienoic, trienoic, tetraenoic, pentaenoic and hexaenoic concentrations of: (a) the older normals, and (b) the atheromatous patients were, respectively: (a) $+0.23,-0.14,+0.14,+0.07$ and +0.11 ; and $(b)-0.207,-0.11,-0.12,+0.03$ and -0.06 . The age span of the students was not sufficient to test for correlations with age.
} 
K. J. Kingsbury et al.
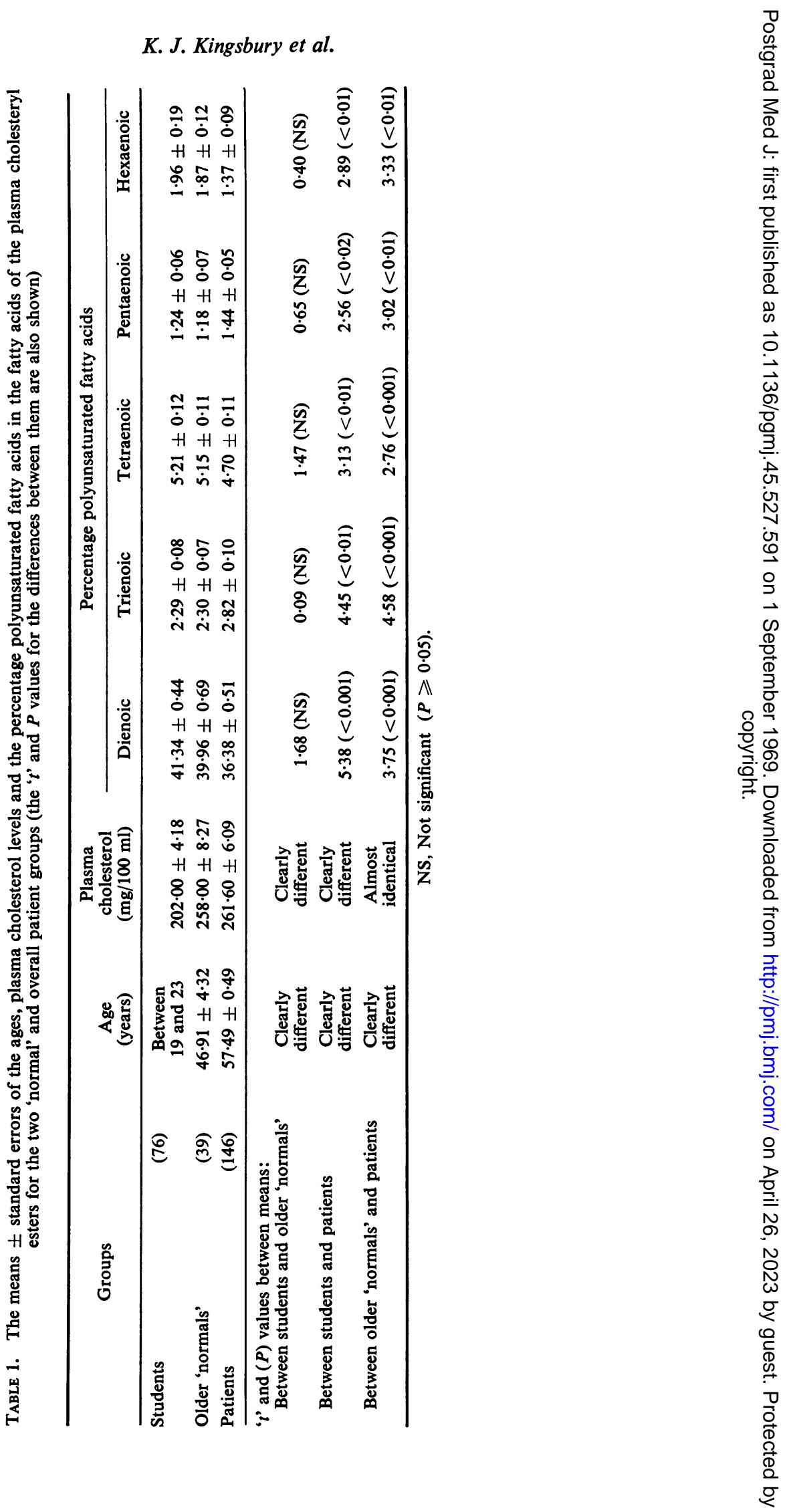
TABLE 2. The mean percentages \pm standard errors of the cholesteryl polyunsaturated fatty acid concentrations for each irregularity and occlusion group*

\begin{tabular}{|c|c|c|c|c|c|c|}
\hline \multirow{2}{*}{ Disease groups } & \multicolumn{5}{|c|}{ Percentage polyunsaturated fatty acids } & \multirow{2}{*}{$\begin{array}{l}\text { No. of } \\
\text { Patients }\end{array}$} \\
\hline & Dienoic & Trienoic & Tetraenoic & Pentaenoic & Hexaenoic & \\
\hline $\begin{array}{r}\text { By occlusions: } \\
0 \\
1 \\
2+\end{array}$ & $\begin{array}{l}39.29 \pm 0.97 \\
36.72 \pm 0.72 \\
33.11 \pm 1.05\end{array}$ & $\begin{array}{l}2.99 \pm 0.17 \\
2.83 \pm 0.18 \\
2.65 \pm 0.16\end{array}$ & $\begin{array}{l}5.00 \pm 0.22 \\
4.57 \pm 0.16 \\
4.62 \pm 0.15\end{array}$ & $\begin{array}{l}1.36 \pm 0.09 \\
1.38 \pm 0.07 \\
1.60 \pm 0.11\end{array}$ & $\begin{array}{l}1.35 \pm 0.11 \\
1.37 \pm 0.18 \\
1.39 \pm 0.20\end{array}$ & $\begin{array}{l}41 \\
62 \\
43\end{array}$ \\
\hline $\begin{array}{l}F \text { ratio } \\
P \text { values }\end{array}$ & $\begin{array}{r}6.64 \\
<0.01\end{array}$ & $\begin{array}{c}2 \cdot 09 \\
\text { NS }\end{array}$ & $\begin{array}{l}1 \cdot 58 \\
\text { NS }\end{array}$ & $\begin{array}{l}1 \cdot 71 \\
\text { NS }\end{array}$ & $\begin{array}{l}0.48 \\
\text { NS }\end{array}$ & \\
\hline $\begin{array}{l}\text { By irregularities: } \\
\text { Slight } \\
\text { Moderate } \\
\text { Extensive }\end{array}$ & $\begin{array}{l}38.08 \pm 0.83 \\
35.23 \pm 0.78 \\
35.25 \pm 1.17\end{array}$ & $\begin{array}{l}2.99 \pm 0.16 \\
2 \cdot 71 \pm 0 \cdot 16 \\
2.66 \pm 0.28\end{array}$ & $\begin{array}{l}4.69 \pm 0.15 \\
4.58 \pm 0.17 \\
4.93 \pm 0.21\end{array}$ & $\begin{array}{l}1.35 \pm 0.08 \\
1.39 \pm 0.06 \\
1.68 \pm 0.14\end{array}$ & $\begin{array}{l}1.44 \pm 0.17 \\
1.25 \pm 0.13 \\
1.43 \pm 0.21\end{array}$ & $\begin{array}{l}59 \\
53 \\
34\end{array}$ \\
\hline $\begin{array}{l}F \text { ratio } \\
P \text { values }\end{array}$ & $\begin{array}{l}2 \cdot 31 \\
\text { NS }\end{array}$ & $\begin{array}{l}0.97 \\
\text { NS }\end{array}$ & $\begin{array}{c}0 \cdot 78 \\
\text { NS }\end{array}$ & $\begin{array}{c}2 \cdot 84 \\
\text { NS }\end{array}$ & $\begin{array}{c}1 \cdot 25 \\
\text { NS }\end{array}$ & \\
\hline Overall means & $36 \cdot 38 \pm 0 \cdot 51$ & $2 \cdot 82 \pm 0 \cdot 11$ & $4 \cdot 70 \pm 0 \cdot 10$ & $1.44 \pm 0.05$ & $1.37 \pm 0.05$ & 146 \\
\hline
\end{tabular}

NS, Not significant, $P>0.05$.

*The significances of the changes between the groups-analysed by two-way analysis of variance-irregularity $v$. occlusionsare shown beneath each column as $F$ ratios and $P$ values (d.f. $2 \times 137$ ).

TABLE 3. The mean \pm standard errors, 2-hr blood sugar and plasma cholesterol concentrations, and ages for each irregularity and occlusion group

\begin{tabular}{|c|c|c|c|c|}
\hline Disease groups & $\begin{array}{c}\text { 2-hr } \\
\text { blood sugar } \\
(\mathrm{mg} / 100 \mathrm{ml})\end{array}$ & $\begin{array}{c}\text { Plasma } \\
\text { cholesterol } \\
(\mathrm{mg} / 100 \mathrm{ml})\end{array}$ & $\begin{array}{c}\text { Age } \\
\text { (years) }\end{array}$ & $\begin{array}{c}\text { No. of } \\
\text { patients }\end{array}$ \\
\hline $\begin{array}{l}\text { Occlusions: } \\
\qquad \begin{array}{l}0 \\
1 \\
2+\end{array}\end{array}$ & $\begin{array}{l}102 \cdot 34 \pm 4 \cdot 81 \\
108 \cdot 77 \pm 4 \cdot 82 \\
102 \cdot 72 \pm 6 \cdot 02\end{array}$ & $\begin{array}{l}256.09 \pm 10 \cdot 24 \\
264.52 \pm 7.77 \\
262.65 \pm 14.58\end{array}$ & $\begin{array}{l}54.54 \pm 1.08 \\
58.11 \pm 0.65 \\
59.42 \pm 0.91\end{array}$ & $\begin{array}{l}41 \\
62 \\
43\end{array}$ \\
\hline $\begin{array}{l}F \text { ratio } \\
P \text { value }\end{array}$ & $\begin{array}{l}0.49 \\
\text { NS }\end{array}$ & $\begin{array}{l}0 \cdot 16 \\
\text { NS }\end{array}$ & $\begin{array}{l}6 \cdot 87 \\
\text { NS }\end{array}$ & \\
\hline $\begin{array}{l}\text { Irregularities: } \\
\text { Slight } \\
\text { Moderate } \\
\text { Extensive }\end{array}$ & $\begin{array}{r}86.02 \pm 3.31 \\
104.94 \pm 4.01 \\
138.82 \pm 9.86\end{array}$ & $\begin{array}{l}247.08 \pm 8.96 \\
269.79 \pm 9.41 \\
274.03 \pm 15.37\end{array}$ & $\begin{array}{l}55.88 \pm 0.76 \\
57.91 \pm 0.85 \\
59.65 \pm 1.05\end{array}$ & $\begin{array}{l}59 \\
53 \\
34\end{array}$ \\
\hline $\begin{array}{l}F \text { ratio } \\
P \text { value }\end{array}$ & $\begin{array}{l}21.51 \\
<0.001\end{array}$ & $\begin{array}{l}1 \cdot 85 \\
\text { NS }\end{array}$ & $\begin{array}{c}4.07 \\
\text { NS }\end{array}$ & \\
\hline Overall means & $105 \cdot 18 \pm 3 \cdot 01$ & $261.60 \pm 6.05$ & $57.49 \pm 0.49$ & 146 \\
\hline
\end{tabular}

The significance of any changes was analysed and presented as for Table 2 . NS, Not significant, $P>0.05$.

\section{Polyunsaturated fatty acids and the arterial lesions}

(a) Occlusions and irregularities by arteriograms. Since the patients and normal subjects differed in all their polyunsaturated fatty acid concentrations, each concentration is compared with the degree of arterial irregularity and number of occlusions in Table 2.

Table 2 shows that the dienoic acid concentrations fell markedly as the number of occlusions increased; the trienoic and tetraenoic acids also decreased, and the pentaenoic acids increased-but these changes did not reach significance. None of the polyunsaturated fatty acid concentrations changed significantly with the degree of atheromatous irregularity.
In contrast, Table 3 shows that the 2-hr blood sugar and plasma cholesterol values increased with the degree of arterial irregularity but not with the number of occlusions. This confirms previous findings (Kingsbury, 1966).

None of the polyunsaturated fatty acid concentrations were related to the plasma cholesterol or 2-hr blood sugar values (correlation coefficients $<0 \cdot 15$ ); and the number of occlusions did not correlate with the degree of arterial irregularity (correlation coefficient $+0 \cdot 14)$.

(b) Stenoses by arteriograms, and the number of occlusions by absent pulses. The age and main biochemical characteristics of the patients with 
TABLE 4. The ages and biochemical characteristics of the patients with 0,1 and $2+$ stenoses, and in the three pulse groups

\begin{tabular}{|c|c|c|c|c|c|}
\hline Disease groups & $\begin{array}{l}\text { No. of } \\
\text { patients }\end{array}$ & $\begin{array}{c}\text { Age } \\
\text { (years) }\end{array}$ & $\begin{array}{l}\text { Glucose } \\
\text { tolerance } 2-\mathrm{hr} \\
\text { blood sugar } \\
(\mathrm{mg} / 100 \mathrm{ml})\end{array}$ & $\begin{array}{c}\text { Plasma } \\
\text { cholesterol } \\
(\mathrm{mg} / 100 \mathrm{ml})\end{array}$ & $\begin{array}{l}\text { Dienoic } \\
\text { acids } \\
(\%)\end{array}$ \\
\hline $\begin{array}{ll}\text { Stenosis } & \\
& 0 \\
& 1 \\
& 2+\end{array}$ & $\begin{array}{r}104 \\
25 \\
17\end{array}$ & $\begin{array}{l}57 \cdot 82 \pm 0.68 \\
56 \cdot 87 \pm 1 \cdot 15 \\
57 \cdot 11 \pm 1.73\end{array}$ & $\begin{array}{l}1.0714 \pm 4 \cdot 15 \\
104.50 \pm 9.37 \\
104.19 \pm 11.66\end{array}$ & $\begin{array}{l}265.09 \pm 7 \cdot 71 \\
248 \cdot 87 \pm 12 \cdot 75 \\
265.06 \pm 19.06\end{array}$ & $\begin{array}{l}37.47 \pm 0.77 \\
33.92 \pm 1.06 \\
35.87 \pm 1.78\end{array}$ \\
\hline$P$ values* & & NS & NS & NS & NS \\
\hline $\begin{array}{r}\text { By Pulses } \\
\text { Occlusions } \\
0 \\
1+ \\
2+\end{array}$ & $\begin{array}{l}25 \\
73 \\
48\end{array}$ & $\begin{array}{l}55 \cdot 12 \pm 1.64 \\
57.09 \pm 0.74 \\
59.35 \pm 0.95\end{array}$ & $\begin{array}{l}103 \cdot 46 \pm 4.90 \\
103 \cdot 67 \pm 4 \cdot 12 \\
105 \cdot 23 \pm 7 \cdot 32\end{array}$ & $\begin{array}{l}266.12 \pm 16.75 \\
254.97 \pm 6.56 \\
268.83 \pm 14.20\end{array}$ & $\begin{array}{l}40 \cdot 25 \pm 1.40 \\
35 \cdot 81 \pm 0.75 \\
35.31 \pm 0.97\end{array}$ \\
\hline$P$ values* & & $\leqslant 0.02$ & NS & NS & $\leqslant 0.02$ \\
\hline Overall & 146 & $57 \cdot 49 \pm 0.49$ & $105 \cdot 18 \pm 3 \cdot 01$ & $261 \cdot 60 \pm 6.08$ & $36.38 \pm 0.51$ \\
\hline
\end{tabular}

NS, not significant $(P \geqslant 0.05)$.

The significance of any changes ( $P$ values) were analysed by single-way analysis of variance.

*' $P$ ' values from single-way analysis of variance.

TABLE 5. $\chi^{2}$ values of the changes in the percentage of abnormally low dienoic acid, high 2-hr blood sugar and plasma cholesterol values in each disease group (estimated from age-standardized numbers)

\begin{tabular}{|c|c|c|c|c|}
\hline \multirow{2}{*}{ Biochemical abnormalities } & \multicolumn{2}{|c|}{ No. of occlusions } & \multirow{2}{*}{$\begin{array}{l}\text { Degrees of } \\
\text { irregularity }\end{array}$} & \multirow{2}{*}{$\begin{array}{l}\text { No. of } \\
\text { stenoses }\end{array}$} \\
\hline & By pulses & By arteriograms & & \\
\hline $\begin{array}{l}\text { Percentage dienoic acids } \\
35 \%\end{array}$ & $7 \cdot 9 *$ & $15 \cdot 4^{* *}$ & $(3 \cdot 6)$ & $(2 \cdot 1)$ \\
\hline $\begin{array}{l}\text { Percentage 2-hr blood sugar } \\
120 \mathrm{mg} / 100 \mathrm{ml}\end{array}$ & $(<2 \cdot 0)$ & $(<2 \cdot 0)$ & $\cdot 20 \cdot 8^{* *}$ & $(<2 \cdot 0)$ \\
\hline $\begin{array}{l}\text { Percentage plasma cholesterol } \\
275 \mathrm{mg} / 100 \mathrm{ml}\end{array}$ & $(<2 \cdot 0)$ & $(<2 \cdot 0)$ & $6 \cdot 0^{*}$ & $(<2 \cdot 0)$ \\
\hline
\end{tabular}

Degrees freedom: 2 .

$*=P<0.05$.

$* *=P<0.01$.

0,1 and $2+$ stenoses estimated from their arteriograms, and in the three occlusion groups assessed by the number of absent pulses are shown in Table 4 (no significant changes were found between these groups in their trienoic, tetraenoic, pentaenoic, or hexaenoic fatty acid concentrations).

No age or biochemical differences were found between the patients with 0,1 and $2+$ stenoses. Patients' ages rose, however, and the percentage of cholesteryl dienoic acids fell as the number of absent pulses increased (single-way analysis of variance, $P<0.05$ ). There were no changes in the plasma cholesterol or 2-hr blood sugar concentrations. These results were similar to those obtained for the patients with 0,1 and $2+$ occlusions as estimated from the arteriograms.

(c) Abnormal biochemical values and the arterial lesions. Abnormal dienoic acid, 2-hr blood sugar and plasma cholesterol concentrations, were taken as $<35 \%$ (Kingsbury et al., 1969), $>120 \mathrm{mg} / 100 \mathrm{ml}$ (Kingsbury, 1968) and $>275 \mathrm{mg} / 100 \mathrm{ml}$ (Kingsbury, 1969), respectively. The incidence of these abnormalities in the various disease groups are shown in Fig. 2. The significance of any differences are shown as $\chi^{2}$ values in Table 5 .

It can be seen that the incidence of abnormally low dienoic acid values showed a pronounced rise with the number of occlusions, whether estimated from the pulses or arteriograms; whereas the incidence of abnormally high 2-hr sugar and plasma cholesterol values only increased with the degree of atheromatous irregularity.

Owing to the wide ranges of the cholesterol values, the rise in the plasma cholesterol concentrations as the degree of atheromatous irregularity increased only reached significance $(5 \%$ level) when 


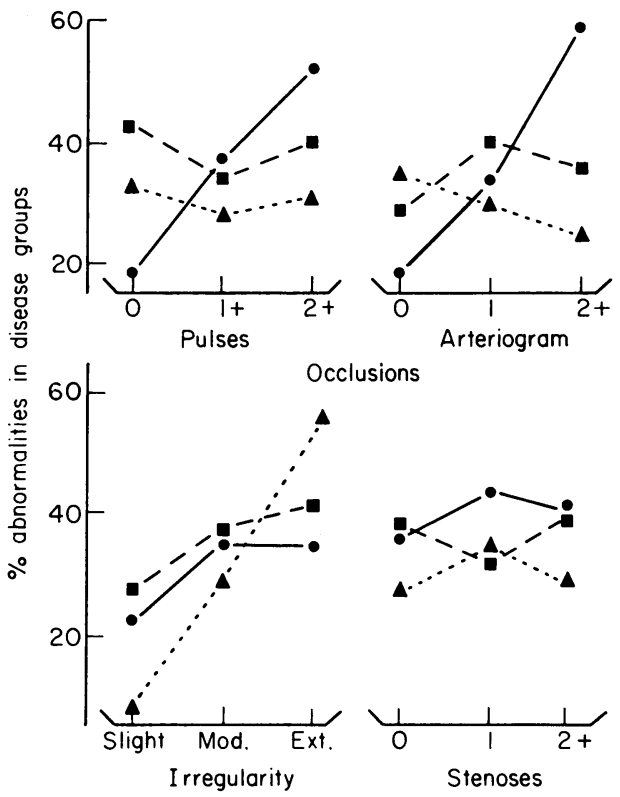

Fig. 2. The percentages of abnormal biochemical values in each disease group (derived from the age-standardized numbers in each group). $\Delta, 2-\mathrm{hr}$ sugar $\geqslant 120 \mathrm{mg}$; dienoic acid $\leqslant 35 \% ; \square$, cholesterol $\geqslant 275$.

considered in terms of the percentage of abnorma values analysed by $\chi^{2}$ tests.

It appears that patients with abnormally low levels of dienoic acids were particularly liable to develop multiple arterial occlusions, whereas the patients with abnormal 2-hr blood sugar and plasma cholesterol levels tended to develop severe atheromatous irregularities.

Thus, out of the polyunsaturated fatty acid differences between the patients and normal subjects, the dienoic acid concentrations showed a marked inverse relationship with the number of arterial occlusions estimated either from the pulses or arteriograms, and whether expressed as mean values analysed by covariance or percentage of abnormal values analysed by $\chi^{2}$ tests. This relationship was independent of the plasma cholesterol and 2-hr blood sugar concentrations, and of the atheromatous irregularities and number of stenoses in the same arteries.

\section{Dienoic acids and age}

Table 3 shows, in addition, that the patients' ages change significantly with the number of occlusions $(P<0.01)$. This raised the question of whether the different dienoic acid concentrations of the occlusion groups had been affected by age.

Fig. 3 shows that in each age group the patients with multiple occlusions had the lowest dienoic acid values. Analysis of variance confirmed that the dienoic acid differences between the occlusion groups ( $F$ ratio 10.93, $P<0.001$ ) were far greater than between the overall age groups ( $F$ ratio $2.93, P>0.05$ ), and so could not simply be the reflection of differences in the patients' ages. Figs. 3 and 4 also show, however, that the dienoic acid concentrations of a particular group of patients-those with multiple occlusions, but not those with patent arteries or a single occlusion-did worsen markedly as their age in-

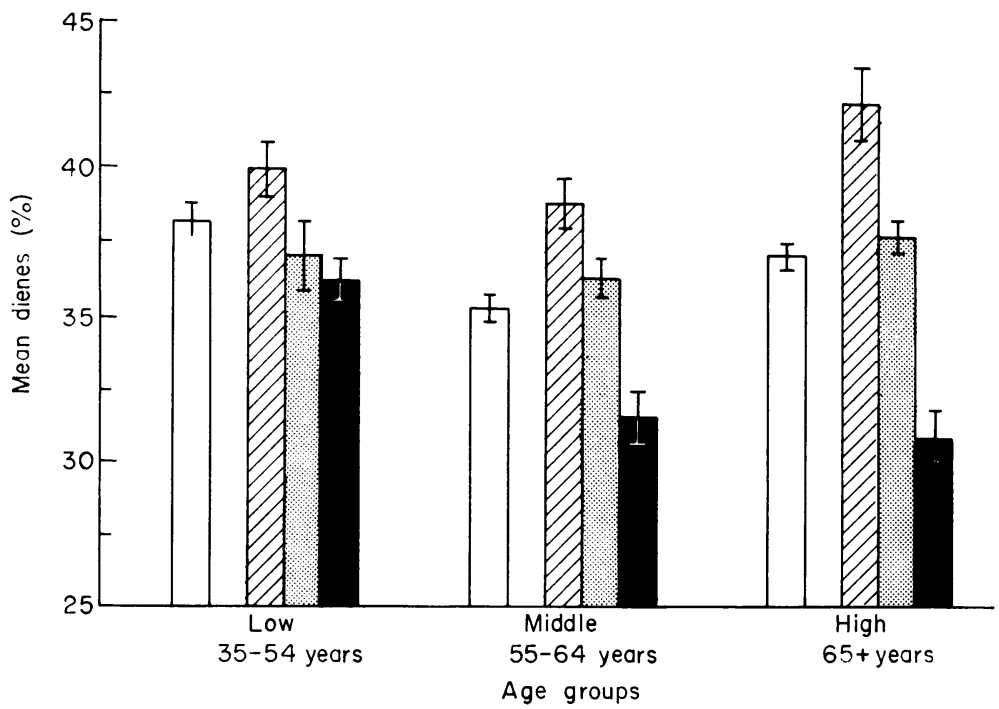

FIG. 3. The mean dienoic acid concentrations of the patients with 0,1 and $2+$ occlusions (by arteriograms) in each age group. Open columns, All patients; hatched columns, 0 occlusions; stippled columns, 1; solid columns, 2 -. 


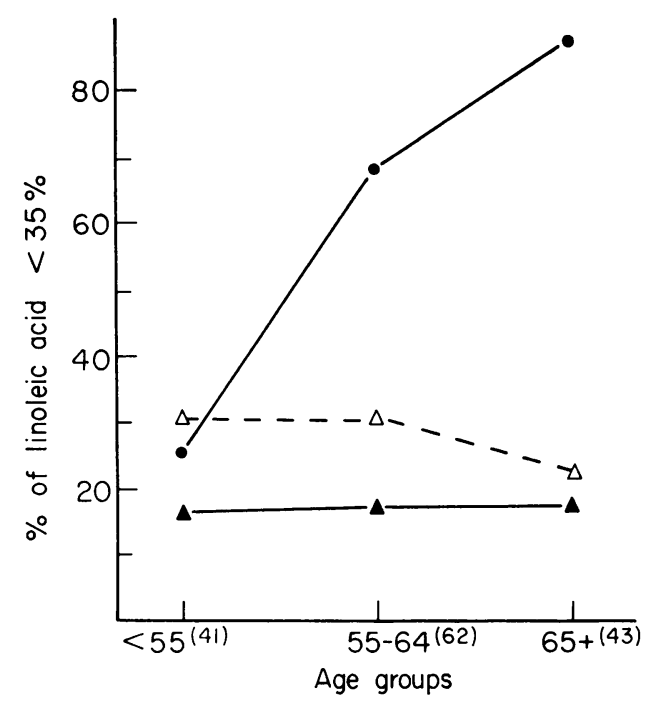

FIG. 4. The percentage of patients in the three occlusion groups with abnormally low concentrations of cholesteryl dienoic acids shown for each age group. Occlusions:, $2+; \triangle, 1 ; \Delta, 0$.

creased. The correlation coefficients between the dienoic acid concentrations and age for the patients with patent arteries, a single occlusion and multiple occlusions were $+0.03,-0.05$ and -0.59 , respectively. Only the last was significant.

Dienoic acid levels, occlusions and myocardial infarction

The relationship between the number of arterial occlusions and the level of the dienoic acid concentrations is shown in Fig. 5.

It can be seen that the patients with multiple occlusions were concentrated in the low dienoic acid range, those with patent arteries in the high range, and those with a single occlusion in the middle range of cholesteryl dienoic acid concentrations. The percentage of patients with multiple occlusions remained steady between 15 and $21 \%$ above $35 \%$ of dienoic acids, whereas below this level the percentage increased sharply to 27,47 and $67 \%$ according to the severity of the fatty acid abnormality. It is clear that the relationship between the percentage of dienoic acid concentrations and the number of occlusions did not increase linearly as the concentrations of dienoic acids decreased, but was markedly potentiated below the level of approximately $35 \%$.

Finally, the percentages of patients in the different occlusion, irregularity, stenosis and pulse groups who developed angina (without myocardial infarction) or myocardial infarction, during a followup period of 3-4 years (as described previously: Kingsbury et al., 1969) are shown in Fig. 6.

The incidence of myocardial infarction, but not angina, increased markedly and linearly with the number of occlusions estimated from the arteriograms $\left(\chi^{2} 11.84, P<0.001\right.$; Armitage, 1955) and to a lesser extent with the number of occlusions assessed from the pulses. There was some increase with the degree of irregularity as reported previously (Kingsbury, 1966) but this was not significant ( $\left.\chi^{2} 3 \cdot 87\right)$. There were no changes with the number of stenoses $\left(\chi^{2} 0 \cdot 86\right)$.

\section{Discussion}

The concentration of all the polyunsaturated fatty acid classes in the plasma cholesteryl esters differed between the patients and normal subjects. Of these differences the dienoic acid concentrations showed a highly significant relationship with the number of arterial occlusions. The remaining polyunsaturated fatty acids showed trends with the

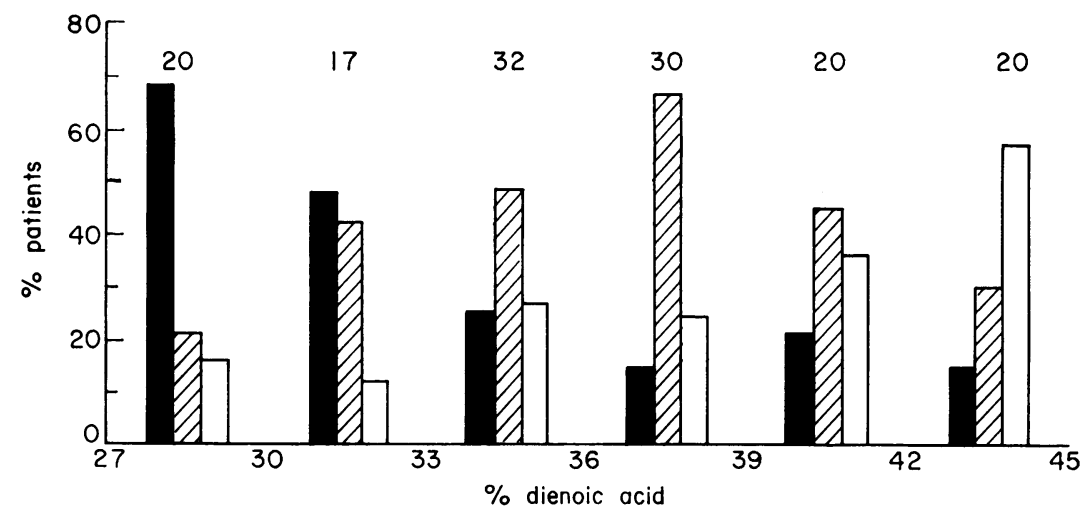

FIG. 5. The percentages of patients at six levels of dienoic acid concentrations in each occlusion group. [The levels were: below $30 \%$ (definitely abnormal), 30-33\% (probably abnormal), $34-36 \%$ (borderline), 37-39\% (probably normal), $40-42 \%$, and $43 \%$ and above (definitely normal).] Open columns, 0 occlusions, hatched columns, 1 ; solid columns, 2 +. 


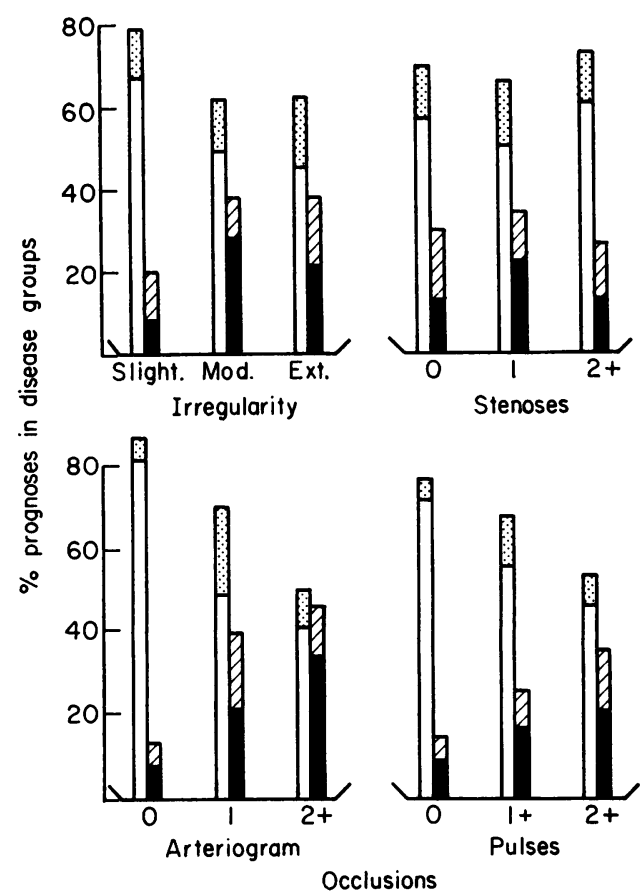

FIG. 6. The percentage of patients alive and well (open columns), alive plus angina (stippled columns), alive plus myocardial infarction (hatched columns) and the vascular deaths (solid columns), in each irregularity, stenosis and occlusion groups.

number of occlusions but these did not reach significance. This was at least partly due to the greater ranges of their values in relation to their means. The significance of these fatty acids remains to be investigated over a larger number of patents.

The polyunsaturated fatty acid differences between the patients and normal subjects were of the inverted ' $w$ ' type of abnormality. This can also be seen in the comparisons between the cholesteryl ester fatty acids from normal plasma and atheromatous plaques (Luddy et al., 1958; Tuna, Reckers \& Frantz, 1958; Wright, Pitt \& Morton, 1959), and from subjects with and without symptoms of coronary disease (Lewis, 1958).

In addition, reduced dienoic (linoleic) and increased trienoic acid levels are found in the plasma phospholipids (Bottcher \& Woodford, 1961), glycerides (Schrade et al., 1960), arterial wall lipids (Geer \& Guidry, 1964; Smith, 1965) and overall depot fats of atheromatous patients (Kingsbury et al., 1962b). The widespread nature of these changes suggests a general metabolic or dietary cause (Kingsbury et al., 1962a, b; Berry et al., 1963; Boyd, 1963; Jurand \& Oliver, 1963; Kingsbury et al., 1964), rather than more local effects such as alterations in the specificity of the cholesteryl esters, or in the distribution of tissue and plasma cholesteryl esters.

Decreased dienoic and tetraenoic, and increased trienoic acid concentrations also occur in animals and children deficient in essential fatty acids (Wiese, Hansen \& Adam, 1958; Jørgensen, Privett \& Holman, 1960; Mohrhauer \& Holman, 1963; Crawford, 1968; Leading Article, 1968). The deficiency state is marked by widespread disturbances of enzyme function (Allmann \& Gibson, 1965; Johnson $\&$ Ito, 1965). The increased trienoic to dienoic or tetraenoic acid ratios in the present patients substantiates previous results (Kingsbury et al., 1962b) and is consistent with a similar relative deficiency of essential fatty acids (Kingsbury et al., 1962b; Kingsbury, 1965). It is now clearly important to investigate if this exists and if it is also associated with fundamental enzyme dysfunctions which contribute to the increased number of arterial occlusions.

Since the patients could only receive arteriograms according to their clinical requirements, it was possible that occlusions might have been missed in the limbs not investigated by arteriography during the initial tests. This was checked by comparing the pulse changes and arteriograms in detail. Of the 146 patients, ninety-four received lumbar aortograms with or without additional femoral arteriograms, twelve received bilateral femoral without lumbar aortograms and forty received a unilateral femoral arteriogram. There were only twelve patients, however, with pulse changes not covered by the arteriograms. Analysis of the results showed that this did not affect the results significantly (data available from K.J.K.).

The classification by pulses provided a further check of the arteriographic assessments. It had the disadvantage that occlusions and stenoses could not always be differentiated or counted precisely and the degree of arterial irregularity could not be estimated at all (data available from K.J.K.). Nevertheless, the similar (though not as marked) biochemical and age differences between the pulse groups supported the dienoic acid-occlusion relationship estimated from the arteriograms.

The mechanisms of this fatty acid-occlusion relationship is at present unknown. The majority of occlusions were probably due to thrombi-as in the coronary arteries (Crawford, Dexter \& Teare, 1961). Arterial thrombi are known to involve the aggregation of platelets (Poole \& French, 1962) and low cholesteryl dienoic acid concentrations are associated with an increased platelet adhesiveness (Evans \& Irvine, 1966). Thus, platelet dysfunctions may be involved. Low concentrations of the polyunsaturated fatty acids could also be expected to increase the synthesis of fibrinogen (Pilgeram \& 
Pickart, 1964, 1968). But whatever mechanisms are concerned, they seem potentiated when the dienoic acid concentrations fall below $35 \%$-as with the development of myocardial infarction, and also do not appear to involve the plasma cholesterol or 2-hr blood sugar levels, since neither were related to the dienoic acid concentrations, the arterial occlusions or the development of myocardial infarction (Kingsbury, 1966; Kingsbury et al., 1969). Epstein (1967) also found no relationship between the 4-year incidence of ischaemic events, and the plasma cholesterol and 2-hr blood sugar concentrations in patients with coronary disease. These findings are consistent with similar processes affecting both the aorto-iliac/femoro-popliteal and coronary occlusions, and show that the significance of the polyunsaturated fatty acids in atherosclerosis should not be considered in terms of their known effects on the plasma cholesterol level (Kingsbury, 1961). In fact, the plasma cholesterol levels are only related (marginally) to the atheromatous irregularities of the arterial wall, whereas the polyunsaturated fatty acid concentrations are markedly related to the occlusions of the arterial lumen.

The development of myocardial infarction was particularly associated with the occlusive aspect of the arterial disease. A similar conclusion was reached from the study of coronary arteries at necropsy (Morris, 1951; Crawford et al., 1961). The present results show, however, that the group of patients with multiple occlusions differed from the remainder by a marked worsening of their dienoic acid concentrations as their age increased. This corresponds to the finding in similar patients that the 2-hr blood sugar values increased with age, but only in those with considerable, but not in those with slight, atheromatous arterial irregularities (Kingsbury, 1968). Taken together these findings suggest that the development of multiple occlusions (or severe atheromatous irregularities) is not simply the effect of time on the same disease tendency, but a different and more malignant category differentiated by the progressive worsening of the biochemistry as age increased.

It is concluded that the abnormal polyunsaturated fatty acid concentrations were not part of a nonspecific biochemical change as previously suggested (Schrade et al., 1960) but were specifically related to the occlusive aspect of the arterial disease, which in turn was associated with the development of myocardial infarction. This suggests that these relationships should now be investigated in detail.

\section{Acknowledgments}

The majority of these studies were carried out in the Surgical Unit, St Mary's Hospital, London, W.2. I would like to thank Professor C. Rob and Professor W. T. Irvine for clinical and laboratory facilities; Dr D. Sutton and the
Radiological Department, St Mary's Hospital, Dr Ian Sutherland of the M.R.C. Statistical Research Unit for help and advice; Mrs E. M. Byard for help in checking the data; and Dr P. J. Robinson, Dr P. Burton, Dr A. Jeffs and Dr A. Simmonds for the development of methods. The follow-up investigations would not have been possible without the pleasant and willing help of the patients, their relatives and general practitioners. Many patients accepted some loss of salary, inconvenience and difficulty to help with these investigations. Their help is sincerely appreciated. I would also like to thank Professor A. Neuberger for his constant support and advice.

Parts of the work have been supported by grants from St Mary's Hospital Endowments Fund, Unilever Ltd, the Tobacco Research Council, Roche Products Ltd, the British Sugar Bureau and the British Nutrition Foundation, Ltd.

\section{References}

Ackman, R.G., Sipos, J.C. \& JANGaARD, P.M. (1967) A quantitation problem in the open tabular gas-chromatography of fatty acid esters from cod liver lipids. Lipids, 2, 251.

Allmann, D.W. \& Gibson, D.M. (1965) Fatty acid synthesis in early linoleic acid deficiency. J. Lipid Res. 6, 51.

Armitage, P. (1955) Tests for linear trends in proportions and frequencies. Biometrics, 11, 375.

Berry, C., Moxham, A., Smith, E., Kellie, A. E. \& NabarRo, J.D.N. (1963) The effect of Atromid on the metabolism of adrenal steroids and on plasma lipid fractions. J. athero. Res. 3, 380.

BöTTCHER, C.J.F. \& WOODFORD, F.P. (1961) Lipid and fatty acid plasma lipoproteins in cases of aortic atherosclerosis. J. athero. Res. 1, 434.

BoyD, G.S. (1963) Hormones and cholesterol metabolism. Control of Lipid Metabolism (Ed. by J. K. Grant), pp. 7998. Academic Press, London.

CraWford, M.A. (1968) Fatty-acid ratios in free-living and domestic animals. Possible implications for atheroma. Lancet, i, 1329.

Crawford, T., Dexter, D. \& Teare, R.D. (1961) Coronary artery pathology in sudden death from myocardial ischaemia. Lancet, i, 181.

Duncombe, W.G. (1963) The colorimetric micro-determination of long-chain fatty acids. Biochem. J. 88, 7.

EPSTEIN, F.H. (1967) Some uses of prospective observations in the Tecumseh Community Health Study. Proc. roy. Soc. Med. $60,56$.

EvANS, G. \& IRVINE, W.T. (1966) Long-term arterial-graft patency in relation to platelet adhesiveness, biochemical factors and anticoagulant therapy. Lancet, ii, 353 .

GeER, J.C. \& GuidRY, M.A. (1964) Cholesteryl ester composition and morphology of human normal intima and fatty streaks. Exp. molec. Path. 3, 485.

Hawk, P.B., Oser, B.L. \& Summerson, W.H. (1947) Practical Physiological Chemistry, 12th edn, p. 540. Churchill, London.

Henly, A.A. (1957) Determination of serum cholesterol. Analyst, 82, 286.

Herb, S.F., Magidan, P. \& Riemenschneider, R.W. (1960) Analysis of fats and oils by gas-liquid chromatography and by ultra-violet spectrophotometry. J. Amer. Oil chem. Soc. 37, 127.

Holman, R.T. \& Hayes, H. (1958) Determination of polyunsaturated acids in lipids of plasma and tissue. Analyt. Chem. 30, 1422.

Huggett, A. St G. \& Nixon, D. A. (1957) Use of glucose oxidase, peroxidase and o-dianisidine in determination of blood and urinary glucose. Lancet, ii, 368. 
Johnson, R.M. \& Ito, T. (1965) Effects of a nutritional deficiency of unsaturated fats on the distribution of fatty acids in rat liver, mitochondrial phospholipids. J. Lipid Res. 6, 75.

Jørgensen, E.A., Privetr, O.S. \& Holman, R.T. (1960) Essential fatty acid deficiency in rats. Biochemistry of Lipids (Ed. by G. Popják), pp. 136-142. Pergamon Press, London.

Jurand, J. \& Oliver, M.F. (1963) Effects of ethyl-chlorophenoxy-butylate on serum cholesteryl, triglyceride and phospholipid fatty acids. J. athero. Res. 3, 547.

KINGSBURY, K.J. (1961) A comparison of the effects of synthetic ethyl arachidonate, edible and cod liver and corn oils on the plasma cholesterol concentrations of normal people. Drugs Affecting Lipid Metabolism (Ed. by S. Garattini and R. Paoletti), pp. 502-507. Elsevier, Amsterdam.

KingSbury, K.J. (1965) The essential fatty acids and human atheroma. Geriatrics, $20,554$.

KINGSBURY, K.J. (1966) The relation between glucose tolerance and atherosclerotic vascular disease. Lancet, ii, 1374.

KINGSBURY, K.J. (1968) Glucose tolerance, age and atherosclerosis. Postgrad. med. J. 44, 944 (Suppl.).

Kingsbury, K.J., Heyes, T.D., Morgan, D.M., Aylott, C., Burton, P.A., Emmerson, R. \& Robinson, P.J.A. (1962a) The effect of dietary changes on the fatty acid composition of normal human depot fat. Biochem. J. 84, 124.

Kingsbury, K.J., Morgan, D.M., Aylott, C., Burton, P., EMmerson, R. \& Robinson, P.J. (1962b) A comparison of the polyunsaturated fatty acids of the plasma cholesteryl esters and subcutaneous depot fats of atheromatous and normal people. Clin. Sci. 22, 161.

Kingsbury, K.J., Morgan, D.M. \& Heyes, T.D. (1964) The analysis of the fatty acids of normal human depot fat by gas-liquid chromatography. Biochem. J. 90, 140.

Kingsbury, K.J., Morgan, D.M., Stovold, R., Brett, C.G. \& ANDERSON, J. (1969) The cholesteryl ester polyunsaturated fatty acids and coronary thrombosis. (In preparation).

LAmbert, M. \& NeISH, A.C. (1950) Rapid method for the estimation of glycerol. Can. J. Res. 28, B, 83 or 535 .

LEAding ArTicle (1968) Essential fatty acids and atheroma. Lancet, i, 1358.

LewIS, B. (1958) Composition of plasma cholesteryl ester. In relation to coronary artery disease and dietary fat. Lancet, ii, 71 .
Luddy, F.E., BARFord, R.A., RIEMENSCHNEIDER, R.W. \& Evans, J.D. (1958). The fatty acid composition of component lipids from human plasma and atheromas. J. biol. Chem. $232,843$.

Macintyre, I. \& Ralston, M. (1954) Direct determination of serum cholesterol. Biochem, J. 56, Proceedings. p.XLIII.

Mohrhauer, H. \& Holman, R.T. (1963) Effects of dietary E.F.A. on polyunsaturated fatty acids of rat heart tissue. Biochemical Problems Lipids (Ed. by Frazer), p. 446. Elsevier, London.

Morgan, D.M. \& Kingsbury, K.J. (1959) Modified hydroxamic acid method for determining total esterified fatty acids in plasma. Analyst, 84, 429.

MORRIS, J.N. (1951) Recent history of coronary disease. Lancet, i, 69.

Pilgeram, L.O. \& Pickart, L.R. (1964) Turnover rate of human plasma fibrinogen: a function of arteriosclerosis. Circulation, Suppl. III, XXIX and XXX, p. III-24.

Pilgeram, L.O. \& Pickart, L.R. (1968) Control of fibrinogen biosynthesis: the role of free fatty acid. J. athero. Res. 8, 155.

Poole, J.C.F. \& FrenCH, J.E. (1962) Thrombosis. J. athero. Res. 1, 251.

Schrade, W., Böehle, E. \& Biegler, R. (1960) Humoral changes in arteriosclerosis investigations on lipids, fatty acids, ketone bodies, pyruvic acid, lactic acid, and glucose in the blood. Lancet, ii, 1409.

SMITH, E.B. (1965) The influence of age and atherosclerosis on the chemistry of aortic intima. J. athero. Res. 5, 224.

Sutton, D. (1962) Arteriography. Livingston, Edinburgh.

Tuna, N., Reckers, L., \& Frantz, T.D. (1958) The fatty acids of total lipids and cholesterol esters from normal plasma and atheromatous plaques. J. clin. Invest. 37, 1153.

WAHLBERG, F. (1966) Intravenous glucose tolerance in myocardial infarction, angina pectoris and intermittent claudication. Acta med. scand. 108, Suppl. 453.

Wiese, H.F., HANSEN, A.E. \& AdAM, D.J.D. (1958) Essential fatty acids in infant nutrition. Linoleic acid requirement in terms of serum di, tri, and tetraenoic acids. J. Nutr. 66 , 345.

Wright, A.S., Pitt, G.A.J. \& Morton, R.A. (1959) Cholesteryl ester fatty acids in atheroma and plasma. Lancet, ii, 594. 


\section{Books received}

Recent Results in Cancer Research. Normal and Malignant Cell Growth. Edited by R. J. M. FRY, M. L. GRIEM and W. H. Kirsten. Pp. 233, illustrated. Berlin, Heidelberg, New York: Springer Verlag; London: William Heinemann Medical Books, 1969. £5 15s.

Home Treatment and Posture in Injury, Rheumatism and Osteoarthritis. By W. E. Tucker. Pp. 135, illustrated. Edinburgh and London: E. \& S. Livingstone, 1969. £1 10s.

A Stereotaxic Atlas of the Human Thalamus and Adjacent Structures. By J. ANDREW and E. S. WATKINS. Pp. 112, illustrated. Edinburgh and London: E. \& S. Livingstone, 1969. 88 .

Diagnosis and Drug Treatment of Psychiatric Disorders. By D. F. KLeIN and J. M. DAvis. Pp. 480. Baltimore: Williams \& Wilkins; Edinburgh and London: E. \& S. Livingstone, 1969. £5 10s.

Computers in Medicine. Edited by J. Rose. Proceedings of a symposium held at Blackburn College of Technology and Design, February 1968 in co-operation with the Institution of Computer Sciences. Pp. 152, illustrated. London: J. \& A. Churchill, 1969. $£ 1$ 10s.

Symposium on the Treatment of Diabetic Retinopathy. Edited by M. F. Goldberg. Pp. 913, illustrated. United States Department of Health, Education and Welfare, 1969. Price not given.

Foetal Autonomy. A Ciba Foundation Symposium edited by G. E. W. Wolstenholme and M. O'Connor. Pp. 326, illustrated. London: J. \& A. Churchill, 1969. £3 10s.

Mechanisms of Toxicity. Edited by W. N. ALDRIDGE. British Medical Bulletin, Vol. 25, No. 3. Pp. 312, illustrated. London: The British Council, 1969. £2.

The Physiology of the Human Kidney. By L. G. Wesson. Pp. 712, illustrated. New York and London: Grune \& Stratton, 1969. \$34.
Scientific Basis of Drug Dependence. Edited by HannaH Steinberg. Pp. 429, illustrated. Biological Council. London: J. \& A. Churchill, 1969. £5.

Enzymopenic Anaemias, Lysosomes and Other Papers. Edited by J. D. Allan, K. S. Holt, J. T. Ireland and R. J. Pollitr. S.S.I.E.M. Symposium No. 6. Pp. 213 , illustrated. Edinburgh and London: E. \& S. Livingstone, 1969. £3.

The Thyroid and The Blood. By G. R. Tudhope. Pp. 102 illustrated. London: William Heinemann, 1969. $£ 1$.

Recent Results in Cancer Research. Scientific Basis of Cancer Chemotherapy. Edited by Georges Mathe. Pp. 96 illustrated. Berlin, Heidelberg, New York: Springer Verlag; London: William Heinemann Medical Books, 1969. £3 3s.

\section{New Editions}

Hewer's Textbook of Histology for Medical Students. Revised by $S$. Bradbury. Ninth edition. Pp. 452, illustrated. London: William Heinemann, 1969. $£ 3$ 10s.

Holland and Brews Manual of Obstetrics. By RoBert PercIVAL. Thirteenth edition. Pp. xiv +866 , illustrated. London: J. \& A. Churchill, 1969. £6.

Recent Advances in Paediatric Surgery. Edited by A. W. WILkINSON. Second edition. Pp. 280, illustrated. London: J. \& A. Churchill, 1969. $£ 310$ s.

Obstetrics. By J. M. Holmes. Concise Medical Textbooks. Second edition. Pp. 301, illustrated. London: Bailliére, Tindall \& Cassell, 1969. $£ 1$ 8s.

Essentials of Human Embryology. By F. D. Allan. Pp. 343, illustrated. London, New York and Toronto: Oxford University Press, 1969. £3.

\section{Erratum}

Kingsbury, K.J., Morgan, D.M., Stovold, R. \& BrETT, C.G. (1969) The relationships between plasma cholesteryl polyunsaturated fatty acids, age and atherosclerosis. Postgrad. med. J. 45, 591.

Page 595, Table 3, column 4 (Age): the $P$ values in both cases should read $<0.01$ not NS.

Also note that the data in Fig. 5 (page 598) and Fig. 6 (page 599) excluded seven patients who were later found to have, or die from, non-vascular disease. 